
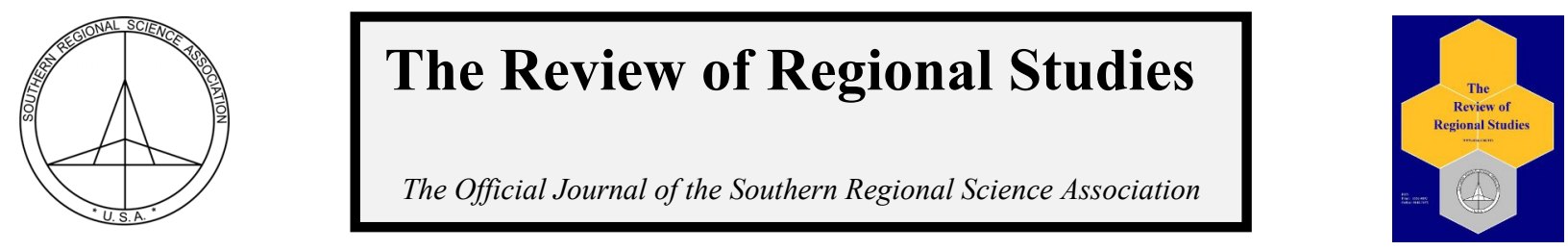

\title{
Geographic Concentration of the Atlantic Sea Scallop Fishery*
}

\author{
Min-Yang Lee ${ }^{\mathrm{a}}$, Cameron Speir ${ }^{\mathrm{a}}$, Andrew Carr-Harris ${ }^{\mathrm{a}, \mathrm{b}}$, Sharon Benjamin ${ }^{\mathrm{a}, \mathrm{c}}$ \\ ${ }^{a}$ NOAA Fisheries, Northeast Fisheries Science Center, USA \\ ${ }^{b}$ Department of Environmental and Natural Resource Economics, University of Rhode Island, USA \\ ' Integrated Statistics, USA
}

\begin{abstract}
The concentration patterns in the Northeast U.S. sea scallop industry are examined from 1996-2014 using generalized indices of concentration and exploratory spatial data analysis. Absolute and relative Theil indices of concentration are computed to describe the regional pattern of concentration within ports over time. Moran's I provides a complementary measure of concentration of activity among neighboring ports. The Moran scatterplots and confidence plots provide insight into local patterns of concentration in this industry. The analysis reveals large changes from year to year in the geographic concentration of the scallop industry, which is likely to be related to natural variability of the environment and regulations enacted by fisheries managers in response to the variability of the environment.
\end{abstract}

Keywords: concentration, specialization, exploratory spatial data analysis, natural resource economics

JEL Codes: F43, R15, R12

\section{INTRODUCTION}

Concentration of economic activity is a frequently studied phenomenon in regional science and economics. ${ }^{1}$ Explanations for concentration of economic activity tend to focus on economies of scale in combination with transportation costs (Krugman, 1991), technical spillovers within industries (Marshall, 1890; Arrow, 1962; Romer, 1986), spillovers between industries (Jacobs, 1969, 1986), spatial variation in government policies (Holmes, 1998), and geographical interpretations of comparative/natural advantages adapted from trade theory (Ohlin, 1967; Fujita and Mori, 1996). Not unexpectedly, some of the most geographically concentrated industrial sectors are the extractive natural resource industries, which are located in and near areas that have large endowments of natural capital (Guillain and Le Gallo, 2010; De Dominicis, Arbia, and De Groot, 2013). In this paper, we characterize and examine the geographic distribution of the Atlantic sea scallop industry with particular focus on changes that occur over time. Marine

\footnotetext{
${ }^{*}$ The views expressed are those of the authors and do not necessarily represent official positions of NOAA Fisheries. The authors thank Frank Bickenbach, Dvora Hart, Eric Thunberg, and the reviewers at RRS for helpful comments on earlier versions of this work. The authors readily accept responsibility for the remaining errors. Portions of this research were funded by the Fisheries Economics \& Social Sciences Program at National Marine Fisheries Service's Office of Science and Technology.

Lee is an Economist at the National Oceanic and Atmostpheric Administration (NOAA) Fisheries - Northeast Fisheries Science Center in Woods Hole, MA, USA. Speir is an Economist at the NOAA Fisheries -Southwest Fisheries Science Center in Santa Cruz, CA, USA. Carr-Harris is a graduate research assistant at University of Rhode Island, Kingston, RI, USA. Benjamin is a GIS Analyst at NOAA Fisheries Northeast Fisheries Science Center, Woods Hole, MA, USA and contracted through Integrated Statistics, Inc. Corresponding Author: M-Y Lee E-mail: Min-Yang.Lee@noaa.gov

${ }^{1}$ See Holmes and Stevens (2004), Combes and Overman (2004), and Fujita, Kanemoto, and Henderson (2004) for overviews of concentration and specialization in North America, Europe, and East Asia respectively.
}

(C) Southern Regional Science Association 2017.

ISSN 1553-0892, 0048-749X (online)

www.srsa.org/rrs 
capture fisheries are particularly interesting because many fish stocks are highly variable from year to year, fishing vessels are very mobile, and the industry is heavily regulated. These regulations could potentially change the natural advantages of any particular port.

Our analysis draws inspiration from the research of Guillain and Le Gallo (2010) and De Dominicis, Arbia, and De Groot (2013), which examine both agglomeration and industrial clustering by combining aspatial global indicators of disproportionality with exploratory spatial data analysis. This research differs from previous efforts in two ways. First, we examine a relatively long time series (1996-2014) of a very narrowly defined industry. This allows us to interpret our results in the context of the many environmental and regulatory changes affecting that particular industry over that time period. Second, we take advantage of the freedom to independently select an appropriate weighting system and reference benchmark described by Bickenbach and Bode (2008). This allows us to examine how scallop fishing has evolved relative to both a uniform distribution and the contemporaneous distribution of fishing. While these disproportionality measures provide insight into the concentration of scallop fishing, they are invariant to spatial ordering, and therefore cannot provide insight into any concentration that may span administrative boundaries (Arbia, 2001). This phenomenon may arise if shoreside infrastructure in one port supports fishing in nearby ports, large "core" ports cast a shadow over nearby ports, or if a port is arbitrarily divided by administrative boundaries. Therefore, we use global and local versions of Moran's $I$ to examine spatial association of scallop landings and specialization in the scallop fishery.

Based on the relative Theil index, we find evidence that the geographic locations of scallop fishing and all fishing are converging. Furthermore, abrupt changes in absolute geographic concentration are correlated with major changes in the fishery and fishing regulations, suggesting that these regulations and environmental conditions can have effects on the distribution of this industry. We find no dominant global pattern of spatial association. Nonetheless, Moran scatterplot maps reveal distinct spatial regimes that are reasonably persistent over time. Geographically small areas with high levels of scallop landings are found amid large swaths of the coast that have minimal scalloping activity. The very active scallop areas sometimes contain multiple ports (complexes) that land large amounts of scallops and sometimes contain single ports that are landing large amounts of scallops.

In the United States, fisheries regulations must be designed to prevent overfishing and achieve "optimum yield" (MSFCMA, 2006). In the scallop fishery, these regulations have typically been a combination of limits on fishing time and closures of parts of the ocean. The scallop fishery has been affected by area closures designed to protect other species of fish. The local abundance of fish stocks, the most important input in production, can vary highly from year-to-year. Large-scale shifts in stock distributions of fish in the Northeast U.S. are also occurring, likely in response to climate change (Lucey and Nye, 2010; Pinsky and Fogarty, 2012). In the future, the Atlantic sea scallop industry is likely to experience both a geographic shift and lower productivity due to decalcification of shells caused by increased ocean acidity (Cooley et al., 2015; Hare et al., 2016).

The changing spatial distribution of the natural resource may alter the relative cost of access and, therefore, change the natural advantages available to specific ports. Fisheries managers understand that spatially explicit fisheries regulations, like permanent and rotating closures of fishing grounds, will affect ports that specialize in a fishery and can result in shifts in the location of that fishery. 
Aspatial policies could also induce shifts in location. For example, if scale economies and thick input markets are important, decreases in quotas could result in fewer "full-service" ports and encourage consolidation of a fishery into a small set of core ports as mobile fishing firms (or fishing rights) migrate away from the periphery. Similarly, if there are positive (negative) spillovers, then increases in catch of one species could attract other fisheries to collocate (disperse). Describing and understanding the port-dynamics of the scallop fishery can begin to provide insight into the relative importance of these economic forces.

\section{THE SEA SCALLOP FISHERY}

The Atlantic sea scallop is a bivalve mollusk that is found on the continental shelf of the northeastern part of the U.S., from North Carolina through Maine. Major fishing grounds include the waters of Georges Bank (GB), Southern New England (SNE), the Mid-Atlantic Bight (MAB), and Gulf of Maine (GOM) at depths up to about 350 feet (Hart and Chute, 2004; Hart and Rago, 2006). Typically, the adductor muscle (meat) is retained for food while the rest of the animal is discarded. Scallops reproduce by producing large amounts of eggs; larvae subsequently drift with water currents before settling to the bottom of the ocean as spat (Hart and Chute, 2004). In GB, currents spin in a clockwise direction, and many of the larvae produced are retained (McGarvey, Serchuk, and McLaren, 1992; Tremblay et al., 1994). Larvae that escape the GB gyre drift south on the prevailing currents, making spatfall in the SNE and MAB regions (Tian et al., 2009). When ocean conditions are favorable, this method of reproduction can result in extremely high abundances of juvenile scallops in localized areas of the ocean. The biological characteristics of sea scallops make them particularly well suited to spatial management: scallops grow relatively quickly, adults have typically low natural mortality, and scallops are relatively immobile after settling on the ocean floor (Hart and Rago, 2006).

There is some spatial heterogeneity in the life history of scallops. Hart and Chute (2009) find that the MAB scallops grow more quickly than GB scallops, although the southern scallops have a smaller maximum size. Sarro and Stokesbury (2009) find heterogeneity in the shell to meat relationship within GB. Hennen and Hart (2012) find that for a given shell height scallops in the MAB have heavier meat than do GB scallops. Interestingly, Hennen and Hart (2012) do not find evidence that increases in scallop density have a negative impact on individual weight.

Commercial fishing is culturally important in the Northeast United States, but it is not particularly large in terms of its share of the overall economy. The New England and MidAtlantic Fishery Management Councils (NEFMC and MAFMC) are responsible for developing recommendations for managing fishing that occurs in federal waters in the northeastern U.S. (from three miles to two hundred nautical miles offshore) and the National Marine Fisheries Service (NMFS) enacts and enforces fishery regulations. The federally managed Atlantic sea scallop fishery primarily uses dredge gear and secondarily uses bottom trawl gear to harvest scallops from the ocean floor (NEFSC, 2014). The scallop fishery is managed with many regulations, including the days-at-sea (DAS) effort control program and rotational openings and closings of parts of the ocean. Under the DAS program, each fishing vessel is allowed to fish up to a maximum number of days. Other important fishing regulations include crew and gear restrictions.

The limited-access fishery has a long history of spatially explicit fishing regulations, with tremendous variation from year to year. Three large areas in GB/SNE (Nantucket Lightship, Closed Area I, and Closed Area II) were closed to commercial bottom-tending gear, including dredges and bottom trawls, to rebuild depleted stocks of groundfish in 1994. Two additional 
areas in the MAB (Hudson Canyon and Virginia Beach) were closed in 1999 to allow high abundances of juvenile scallops to mature. The scallop fleet was also allowed access to a portion of one of the closed GB areas in 1999; this access-area program was broadened into other areas in 2000. From 1999-2003, individual vessels were allowed to take a limited number of trips into these access areas; these trips were associated with a possession limit, implemented on meat weights. Fishing in these trips also used DAS; therefore, a vessel taking one of these special trips was substituting fishing in an access area for fishing in a "normal" open area.

In 2004, a formal rotational program was implemented consisting of access areas, open areas, and closed areas. ${ }^{2}$ Under this system, when resource managers detect high abundances of small scallops in an area, that area can be closed to fishing to allow the scallops to grow larger. This increases value through both higher catch and higher prices associated with larger scallops. When opened, fishing vessels are allocated a number of trips into the access areas with a corresponding possession limit. Under the formal rotational program, fishing in the access areas no longer requires using open-area DAS. Two additional areas (Elephant Trunk and Delmarva) were added to the program, and one (Virginia Beach) was removed from the program since its closure did not enhance local scallop biomass.

As access areas are opened and closed, the relative costs of fishing from a port change as well. Increases in travel time to the rotational areas leads to increased expenditures on fuel. Increases in travel time to open areas are even costlier because fishing vessels must use scarce DAS to steam instead of actively fish. Fishing vessels are more footloose than traditional manufacturing firms and can respond to changes in costs by changing locations.

The access and closed areas in effect in 2014 are illustrated in Figure 1 along with the port-level landings share of scallop, averaged over the 1996-2014 time period. New Bedford, MA has been an important port for the scallop fishery for years: in 1938 approximately 48 percent of all scallops were landed in New Bedford, MA and New Bedford's share fluctuated between 42 and 67 percent during the study period. Figure 1 suggests that certain sets of policies could result in changes in industrial concentration. For example, in 2003 the three northern-most access areas were all closed, placing the northern ports at a disadvantage. However, in 2006, all of the access areas except for the Nantucket Lightship area were closed, placing the southern ports at a relative disadvantage.

We use the number of full-time vessels, access area trips allocated, and the access area possession limits to construct the implied scallop allocations to the MAB and GB/SNE access areas. These implied allocations are a measure of the relative importance of fishing opportunities in the northern and southern areas. Combined with total catch of scallops, this illustrates the importance of the access area program to the fishery and the large year-to-year spatial variation in available fishing areas $^{3}$ (Table 1). Ports located in the south held a comparative advantage due to relatively high allocations to the MAB areas during three periods: 1996-1998, 2001-2005, and 2007-2010. Ports located in the north held a comparative advantage due to relatively high allocations to the $\mathrm{GB} / \mathrm{SNE}$ areas during three periods:

\footnotetext{
${ }^{2}$ Also in 2004, sections of the ocean were closed to protect Essential Fish Habitat (EFH) for groundfish and scallops. Scallop and groundfish EFH closures partially overlapped and in 2011 the boundaries of the scallop EFH closure areas were adjusted to closely match groundfish EFH areas. There is minimal scallop fishing in the groundfish EFH areas in the Gulf of Maine.

${ }^{3}$ From 1998-2014, vessels were allocated trips with a possession limit. Until 2006, vessels could end a trip early (perhaps for safety reasons) and take a subsequent partial trip with a slight penalty. The penalty was removed in 2006, and the "trip" allocations have functioned as an IFQ since then.
} 


\section{Figure 1: Overview of the Study Area}

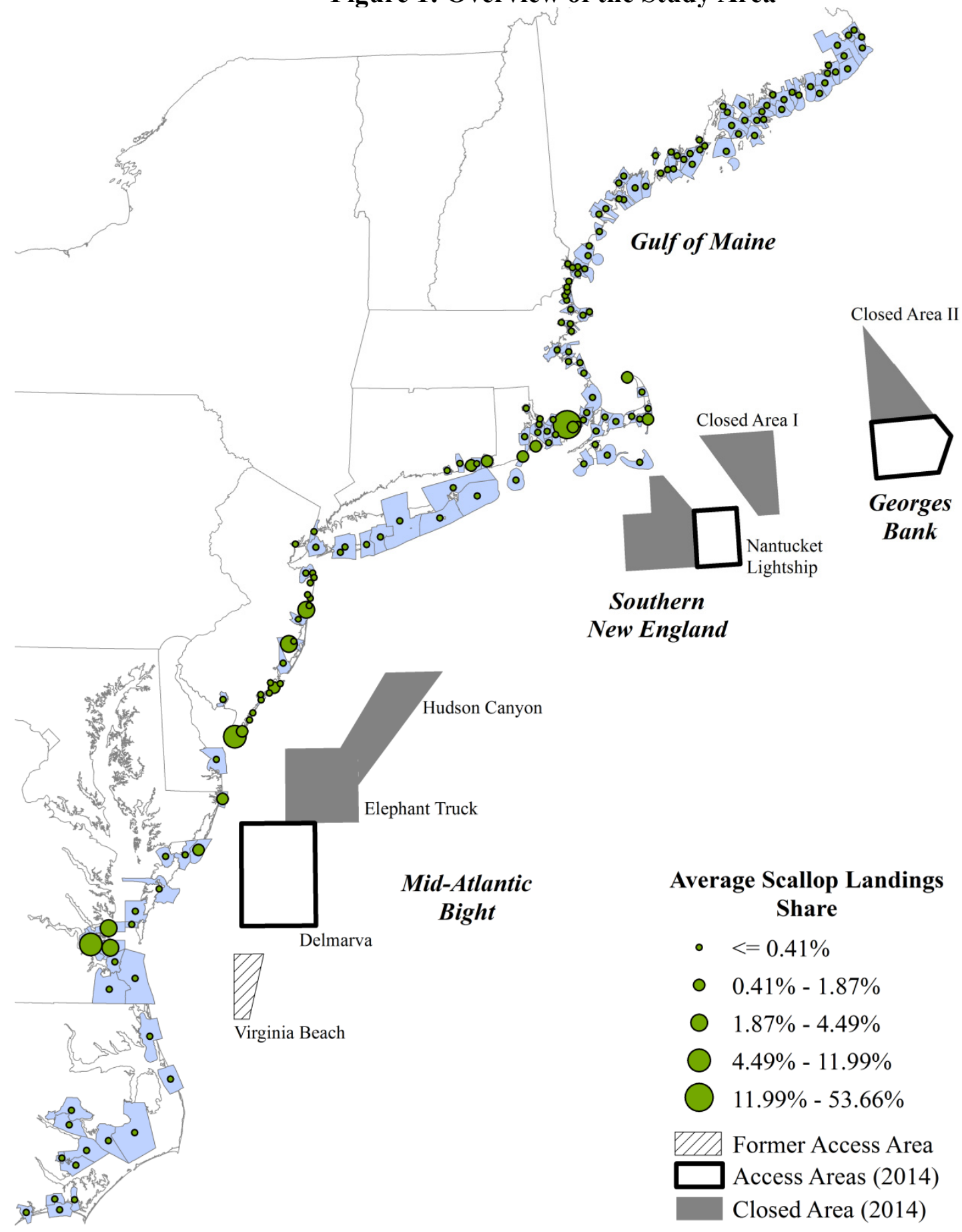

Spatial management measures active in 2014 and the share of scallop landings in each port averaged over the period 1996-2014 included for reference. 
Table 1: Full-time Scallop Vessels, Days-at-Sea allocations, Implied Access Area Allocations (millions of pounds) and Total Landings (millions of pounds).

\begin{tabular}{rrrrrr}
\hline & \multicolumn{5}{c}{ Allocations } \\
\cline { 2 - 4 } Year & $\begin{array}{rrrrr}\text { Full Time } \\
\text { Vessels }\end{array}$ & $\begin{array}{r}\text { Days-at-Sea } \\
\text { per Vessel }\end{array}$ & $\begin{array}{r}\text { Mid-Atlantic } \\
\text { Access Areas New England Access Areas }\end{array}$ & Total Landings \\
\hline 1996 & 224 & 182 & N/A & N/A & 17.1 \\
1997 & 204 & 164 & N/A & N/A & 13.4 \\
1998 & 205 & 142 & N/A & N/A & 11.9 \\
1999 & 211 & 120 & 0 & 6.3 & 22.3 \\
2000 & 221 & 120 & 0 & 11.1 & 34.0 \\
2001 & 235 & 120 & 12.0 & 0 & 47.2 \\
2002 & 258 & 120 & 13.9 & 0 & 50.6 \\
2003 & 274 & 120 & 17.3 & 0 & 56.2 \\
2004 & 288 & 62 & 20.7 & 15.6 & 64.0 \\
2005 & 303 & 40 & 16.4 & 10.9 & 54.0 \\
2006 & 315 & 52 & 0 & 28.4 & 56.8 \\
2007 & 319 & 51 & 17.2 & 11.5 & 61.2 \\
2008 & 310 & 35 & 22.3 & 5.6 & 52.1 \\
2009 & 305 & 37 & 22.0 & 5.5 & 57.0 \\
2010 & 304 & 38 & 16.4 & 5.5 & 55.7 \\
2011 & 308 & 32 & 11.1 & 11.1 & 57.1 \\
2012 & 310 & 34 & 8.4 & 14.0 & 56.0 \\
2013 & 306 & 33 & 2.7 & 5.3 & 39.2 \\
2014 & 306 & 31 & 3.7 & 3.7 & 34.8 \\
\hline
\end{tabular}

Note: Mid-Atlantic Access Areas are: Delmarva, Elephant Trunk, Hudson Canyon, and Virginia Beach. Georges Bank \& Southern New England Access Areas are: Nantucket Lightship, Closed Area I, and Closed Area II.

1999-2000, 2006, and 2011-2013. By 2014, the GB/SNE and MAB area allocations were equal and small relative to total catch.

Over the 1996-1999 period, the DAS allocation was cut by one-third as part of a plan to rebuild depleted stocks of sea scallops. In 2004, allocated DAS were decreased by an additional 50 percent when fishing inside access areas no longer required using DAS. By 2012, allocated DAS had been cut by almost 50 percent relative to the 2004 level in response to increases in landings-per-trip and mandates to not exceed catch limits (NEFMC, 2014). Landings of scallops in the mid-1990s were low due to low biomass and restrictive fishing regulations designed to allow the scallop biomass to grow. Prior to the 1994 closures of many fishing grounds, the scallop fishery was experiencing "growth overfishing," in which there is excess harvest of small individuals before they reach the economically optimal size (Repetto, 2002). Edwards (2004) and Hart and Rago (2006) illustrate improvements in economic and biological metrics for the fishery after those closures and other regulations that reduced fishing pressure were enacted. By 2004, scallop biomass dramatically increased from historical lows, and GB/SNE biomass has grown faster and to higher levels than the MAB biomass (Hart and Rago, 2006). Biomass remains historically high; however MAB biomass has declined recently as a result of (planned) high levels of catch and lower-than-expected reproduction. In 2013, the biomasses in GB and MAB regions were fourteen and seven times greater than the respective biomasses in 1993 (Figure 2; NEFSC, 2015). Landings have remained at historically high levels, varying from 41-64 million pounds, before declining in 2013 and 2014. 
Figure 2: Biomass of Scallops in Georges Bank and Mid-Atlantic (NEFSC, 2015)

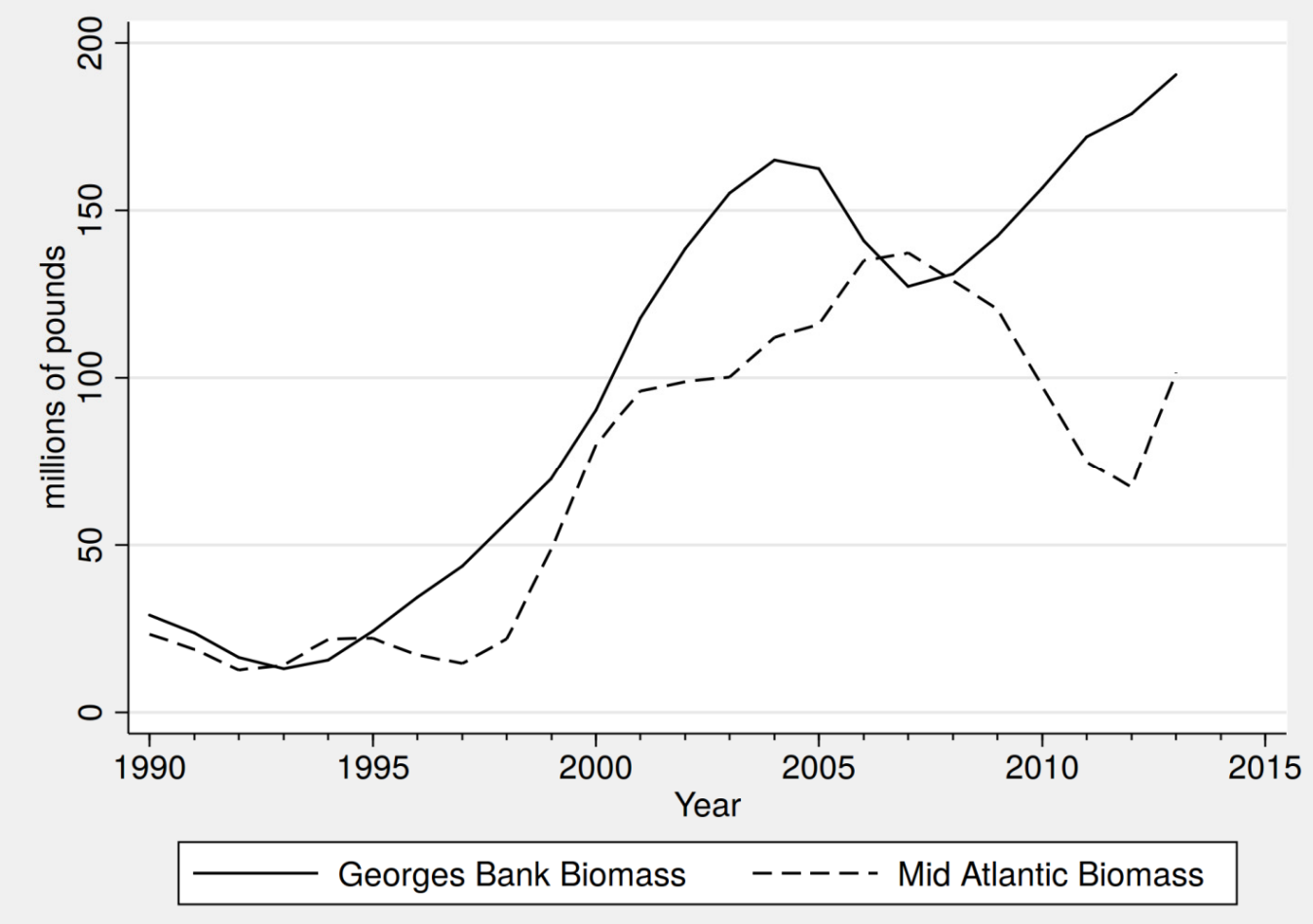

The scallop fishery is large in terms of value, recently averaging around $\$ 400$ million in ex-vessel value. Measured by weight, the scallop fishery has increased in importance slightly in the Northeast region of the U.S. (Figure 3a). Over the study period, catch in many of the other Northeast fisheries has decreased as fisheries managers have tried to rebuild depleted stocks (Brodziak et al., 2008; Murphy et al., 2015). Scallops have grown to be dominant in terms of value in the Northeast region due to relatively high scallop prices (Figure 3b). In general, higher prices are paid for larger scallops (NEFMC, 2015) and scallops caught in MAB receive slightly lower prices due to their tendency to exude more liquid both before and after delivery (Georgianna, pers. comm.).

Figure 3: Scallop and "Other Species" (a) Landings and (b) Value.

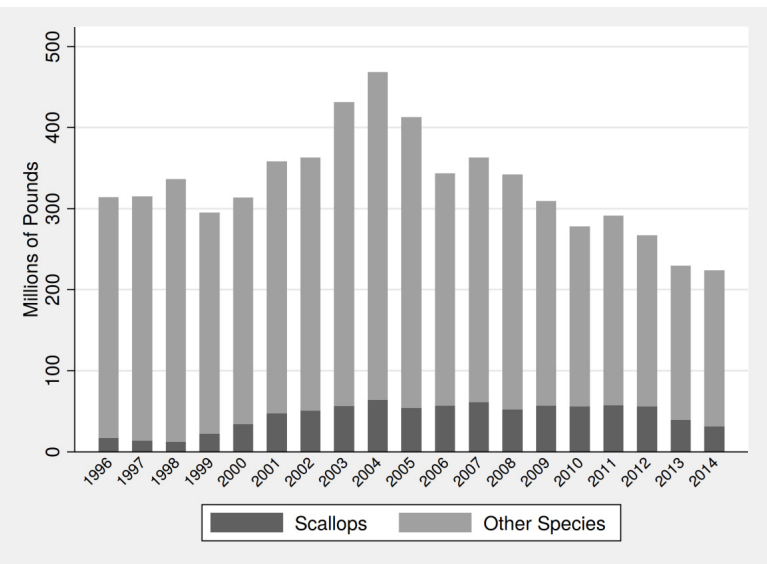

(a)

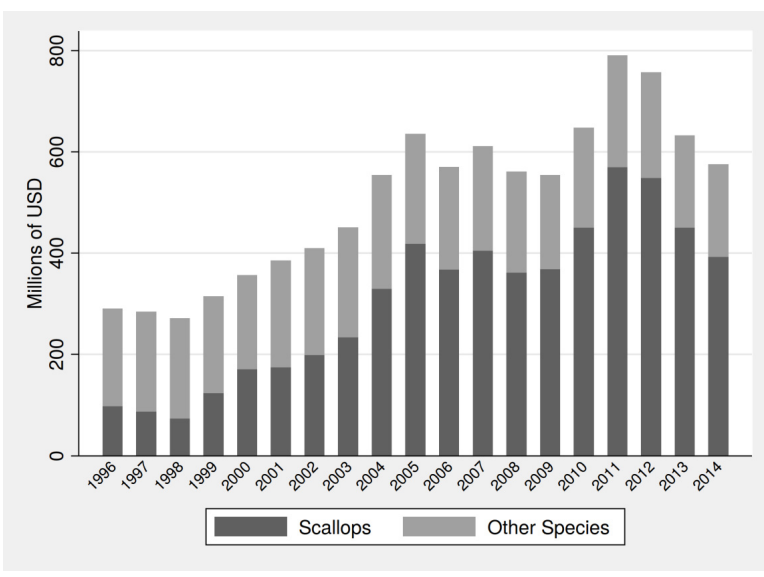

(b) 
Scallops are both caught and landed farther south than other species in the Northeastern U.S. (Figure 4). For scallops and other fisheries, catch locations are south of landing locations, landing latitude changes more slowly than catch latitudes, and both catch and landing locations display northward trends discussed previously in the fisheries literature ${ }^{4}$ (Lucey and Nye, 2010; Pinsky and Fogarty, 2012). The mean latitude of the scallop fishery is quite variable. The scallop fishery shifted south during three periods (1999-2004, 2006-2008, and 2013-2014) and moved rapidly north twice (2004-2006 and 2010-2013).

\section{DATA AND METHODS}

Two sets of commercial fishing data collected by NMFS in the Northeast region form the backbone of the data used for this research: mandatory vessel trip reports and dealer reporting systems. The vessel trip report data are used as the source for landings, port, and trip level information. The dealer data are used to construct prices needed to compute value. These data collection processes began in 1994; however, because the first two years of the collected data are regarded as low-quality, we begin our analysis in $1996 .{ }^{5}$ We aggregate to the U.S. Census county subdivision to construct annual, port-level scallop landings and value. ${ }^{6}$

We also construct a measure of "total fishing" activity using landings and value derived from species of fish with federal mandatory reporting requirements in $1996 .^{7}$ Fishing vessels that held permits to catch those species were required to report catch of all species, including catch of species without reporting requirements. Similarly, buyers of any of these species were required to report purchases of all species, including purchases of species without reporting requirements. This benchmark omits species for which federal reporting was adopted after 1996 (such as monkfish, herring, and scup) and species for which there is currently no federal reporting requirement (such as American lobster, croaker, and weakfish). Some of these species are caught in state waters (less than three miles from shore) by fishing vessels with no federal fishing permits. ${ }^{8}$ The fishing activity in our benchmark is likely located both farther north and farther from shore than the "true" location of all fishing.

\subsection{Measuring Geographic Concentration using a Generalized Theil Index}

Bickenbach and Bode (2008) noted that weights, references, and aggregation functions used to construct spatial disproportionality measures can all be selected independently and should be chosen based on the research question. We use the generalized version of the Theil index described in Bickenbach and Bode (2008), which nests many of the frequently used Theil

\footnotetext{
${ }^{4}$ When we examine the catch and landing locations for the other species individually, most have northerly trend lines with small slopes. The exceptions are squid and mackerel, which are small, mobile fish that are found at the top of the water column.

${ }^{5}$ There are numerous data errors, likely due to inexperience of vessel operators with the new reporting requirements, in the first two years of this program that are difficult to diagnose or correct.

${ }^{6}$ While vessel captains report the port of landing, the precision of this particular data field seems to have varied across captains and over time. The county subdivision strikes the best balance between high spatial resolution and potential error in classification. We use the U.S. Census 2013 definitions of the county subdivisions.

${ }^{7}$ In addition to sea scallop, this includes groundfish (cod, haddock, pollock, redfish, wolffish, ocean pout, winter flounder, yellowtail flounder, American plaice, sand dab, witch flounder, and halibut), surf clam, ocean quahog, summer flounder, mackerel, loligo and illex squid, and butterfish.

${ }^{8}$ The reason for omitting these species is to ensure a consistently defined benchmark; while catch data exist for these species, these cannot be treated as a census and including them may not be representative of the geographic distribution of "marine fishing."
} 
indices. The general form of the Theil index of concentration for industry $i$ in time period $t$ is written as:

$$
T_{i t}^{c}=\sum_{r=1}^{R} w_{r t} \frac{\frac{x_{i r t}}{\Pi_{i r t}}}{\sum_{r} w_{r t} \frac{X_{i r t}}{\Pi_{i r t}}} \ln \left(\frac{\frac{x_{\text {irt }}}{\Pi_{\text {irt }}}}{\sum_{r} w_{r t} \frac{X_{\text {irt }}}{\Pi_{\text {irt }}}}\right),
$$

where $X_{\text {irt }}$ is the measure of economic activity of industry $i$ in region $r$ and time $t$, and $\Pi_{\text {irt }}$ is a reference distribution of activity that formalizes the null hypothesis of "no concentration" for industry $i$. The regional weights, $w_{r t}$, reflect the importance of each observed unit and are selected so that $\sum_{\mathrm{r}} w_{r t}=1$.

In theory, the reference distribution, $\Pi_{\text {irt }}$, can be almost anything (Bickenbach and Bode, 2008). Most studies of concentration, specialization, or localization that construct a "relative" measure use a higher-level aggregate, such as sectoral or total employment, in region $r$ as the reference (Brülhart and Traeger, 2005; Cutrini, 2010; Bickenbach, Bode, and Krieger-Boden, 2010). Bickenbach and Liu (2013) is a notable exception that uses regional population and regional per-capita income as a reference distribution to examine inequality in higher education opportunities relative to both demand and supply for higher education.

We calculate the Theil index using one time-varying and one time-invariant reference distribution. We use "all fishing" as our time-varying, relative reference $\left(\Pi_{r t}=\sum_{\mathrm{i}} \mathrm{X}_{\mathrm{irt}}\right)$. This relative Theil index embeds the null hypothesis that the scallop fishery is geographically distributed in proportion to all fishing activity and removes the effects of broader sector-level forces (such as changes in the location of final consumers or prices of fuel) that can affect geographic concentration. Increases (decreases) in this relative Theil index can be interpreted as evidence that the distribution of scallop fishing across regions is becoming less (more) similar to the broader fishing industry. This reference has one disadvantage in this empirical setting: because the value share of fishing has become dominated by scallop, the Theil index constructed using value will be predisposed to showing a decrease in concentration over time. Still, the scallop industry's quantity share of fishing has been relatively consistent over time and should not be subject to this effect. We use the uniform distribution as our time-invariant reference $\left(\Pi_{r}=1\right)$; we refer to a Theil index calculated using the uniform distribution for a reference as the absolute Theil index. This reference embeds the (somewhat implausible) null hypothesis that scallop fishing is distributed uniformly across ports in the Northeast U.S. The uniform reference has a relatively easy and intuitive interpretation. Increases (decreases) in the absolute Theil index are evidence that more (fewer) scallops are being landed in fewer (more) ports.

The appropriate choice of weights implicitly defines which "units" enter the aggregation function and is directly related to the research question (Brülhart and Traeger, 2005; Bickenbach and Bode, 2008). Because we are examining and characterizing changes in the geographic concentration of the scallop industry across the Northeast U.S., we treat each unit of scallop activity (pound of scallop or dollar of scallop value) as equally important, regardless of the location in which it is landed. This implies weighting each observation based on each port's share of scalloping activity for all indices, ${ }^{9}\left(\mathrm{w}_{\mathrm{rt}}=\frac{X_{i r t}}{\sum_{r} X i_{r t}}\right)$. Alternatively, a research question that

\footnotetext{
${ }^{9}$ A frequently used set of weights is the "total value" in a region. A total value weighting system would treat each unit of aggregate fishing activity (pounds or value of fish) as equally important, regardless of the location in which it is landed. In our opinion, this would be a more reasonable choice for examining port-level industrial specialization or "localization" of all fishing activity, but less appropriate for examining concentration of a particular industry.
} 
focuses on the concentration of fishing in ports might warrant equal weights for each port, $\left(\mathrm{w}_{\mathrm{rt}}=\frac{1}{R}\right)$. By treating each port as equally important in the aggregation function, this weighting will necessarily lead to an unequal weighting of each unit of scallop activity in the aggregation function. ${ }^{10}$

\subsection{Global Indicators of Spatial Association}

The disproportionality indices are invariant to geographical rearrangement of the spatial units. Previous researchers have paired concentration indices with exploratory spatial data analysis conducted on either location quotients or modified location quotients (Guillain and Le Gallo, 2010; De Dominicis, Arbia, and De Groot, 2013). This allows for examination of spatial association of industrial specialization. Many types of spatial association in the scallop fishery industry are possible. For example, neighboring ports have similar travel times to scalloping grounds, which may lead to positive spatial association of scallop activity. Administrative boundaries that artificially split ports would also lead to positive spatial association (Arbia, 2001). Port-level scale economies (perhaps in scallop processing or scallop gear maintenance) may lead to core-periphery geography when a "core" port attracts scalloping that would otherwise occur in a neighboring port, leading to negative spatial association of scallop activity. These phenomena would be detectable by conducting spatial analysis on raw measures of scallop activity. ${ }^{11}$ Alternatively, spatial variations in the productivity of fishing grounds (for scallops and other fish) may lead to positive spatial association of specialization measures, like location quotients. For example, groups of ports located close to scalloping grounds would specialize in scallops while another group of ports located close to cod grounds would specialize in cod.

To further our understanding of the spatial distribution of fishing activity, we calculate Moran's $I$, a commonly used global measure which can identify the dominant form of spatial autocorrelation if it exists. Moran's $I$ is a global measure that summarizes the spatial association of all spatial units:

$$
I=\sum_{p=1}^{R} \sum_{q=1}^{R} w_{p q}\left(Y_{p}-\bar{Y}\right)\left(Y_{q}-\bar{Y}\right) / \sum_{p=1}^{R}\left(Y_{p}-\bar{Y}\right)^{2}
$$

A pre-determined $R \times R$ spatial weights matrix, $W$, with individual elements $w_{p q}$, quantifies the spatial association between regions $p$ and $q$ in the study area. Many different weight matrices are possible and have been used in the literature. We present results obtained using an inversedistance matrix truncated at five decimal degrees. ${ }^{12}$ This is a commonly used class of weights matrix (eg: Fingleton, 1999; Baumont, Ertur, and Le Gallo, 2006) and will allow distant ports to be neighbors since fishing grounds may be common and fishing vessels are mobile. We present results of our spatial analysis on both scallop fishing activity (quantities) and the location quotients constructed based on value. Statistical significance is assessed using a random

\footnotetext{
${ }^{10}$ Unless the distribution of scalloping is uniform across the ports.

11 Spatial analysis is not usually conducted using un-transformed levels because regions with large populations have larger amounts of economic activity than regions with lower populations. Analysis of nonnormalized data is likely to simply reflect this fact, misattributing the spatial association of the aggregate economy to the spatial association of a particular industry. We suspect that this is less of an issue with the scallop fishery, which is still relatively small compared to the regional economy in terms of value, employment, and land use.

${ }^{12}$ Our results are robust to other reasonable spatial weights matrices. We also use a row-standardized inverse distance matrix and quadratic inverse distance (un-standardized and row-standardized).
} 
permutations test in which the $Y$ vector is repeatedly permuted and Moran's $I$ is calculated to form a distribution of $I$ that would occur if $Y$ were independent of spatial ordering (Anselin, 1995).

\subsection{Local Indicators of Spatial Association}

Anselin (1995) decomposes Moran's $I$ into contributions derived from each region, $I_{i}$, the local Moran's $I$ :

$$
I_{i}=\frac{\left(Y_{i}-\bar{Y}\right)}{\sum_{r}\left(Y_{r}-\bar{Y}\right)^{2} / R} \sum_{r=1}^{R} w_{p q}\left(Y_{r}-\bar{Y}\right)
$$

The local version of Moran's $I$ is a way to identify clusters of similar values across space. Positive values of the local Moran's $I$ statistic indicate positive spatial association (high values surrounded by high values or low values surrounded by low values), while negative values indicate negative spatial association (high values surrounded by low values or vice versa). Statistical inference regarding departures from the null hypothesis of no spatial association is assessed using the conditional randomization test described in Anselin (1995), in which the location of port $i$ is fixed while the location of the other ports are repeatedly permuted to generate the distribution of $I_{i}$ that results from spatial randomness in the location of other ports. To explore local patterns of spatial association, we use a Moran scatterplot and significance map.

\section{RESULTS AND DISCUSSION}

\subsection{Theil Indices of Concentration}

The relative Theil index shows a decreasing time trend, though it is nonmonotone with brief reversals in 2003, 2008, and possibly 2014 (Figure 4). The quantity and value indices have the same general trends, although the value based index is much lower in magnitude, reflecting the large value share of scallops. This indicates that the spatial distribution of scallop fishing and "all fishing" in the Northeast U.S. are converging. During the mid-1990s, scallop fishing has been occurring farther south than other fishing. Fishing in general has been moving northward, and scallop fishing has moved northward more quickly than other fisheries (see Figure 5). This finding of convergence may be caused by the scallop fishery moving to ports used by other fisheries, those other fisheries moving to ports where the scallop fishery is active, or a combination of these phenomena. The methods we use here cannot distinguish between these two alternative explanations.

A few notable year-over-year changes in the relative Theil indices illustrate how spatial management can shift the distribution of the fishing industry by changing the relative advantages of ports. In 2006, the scallop fishery quickly and temporarily moved north in response to the closure of all the MAB areas, while the other fisheries shifted slightly south. The relative Theil index reached a new low in this year. From 2007-2009, the MAB areas were open with high allocations, driving the scallop industry south and leading to a short-lived spike in the relative Theil index. From 2009-2012, the scallop industry moved north faster than the broader industry as the allocations to GB/SNE were large relative to the MAB allocations. This reversed in 2014 as scalloping again shifted south. 
Figure 4: The Relative Theil Index Computed using Value and Quantities.

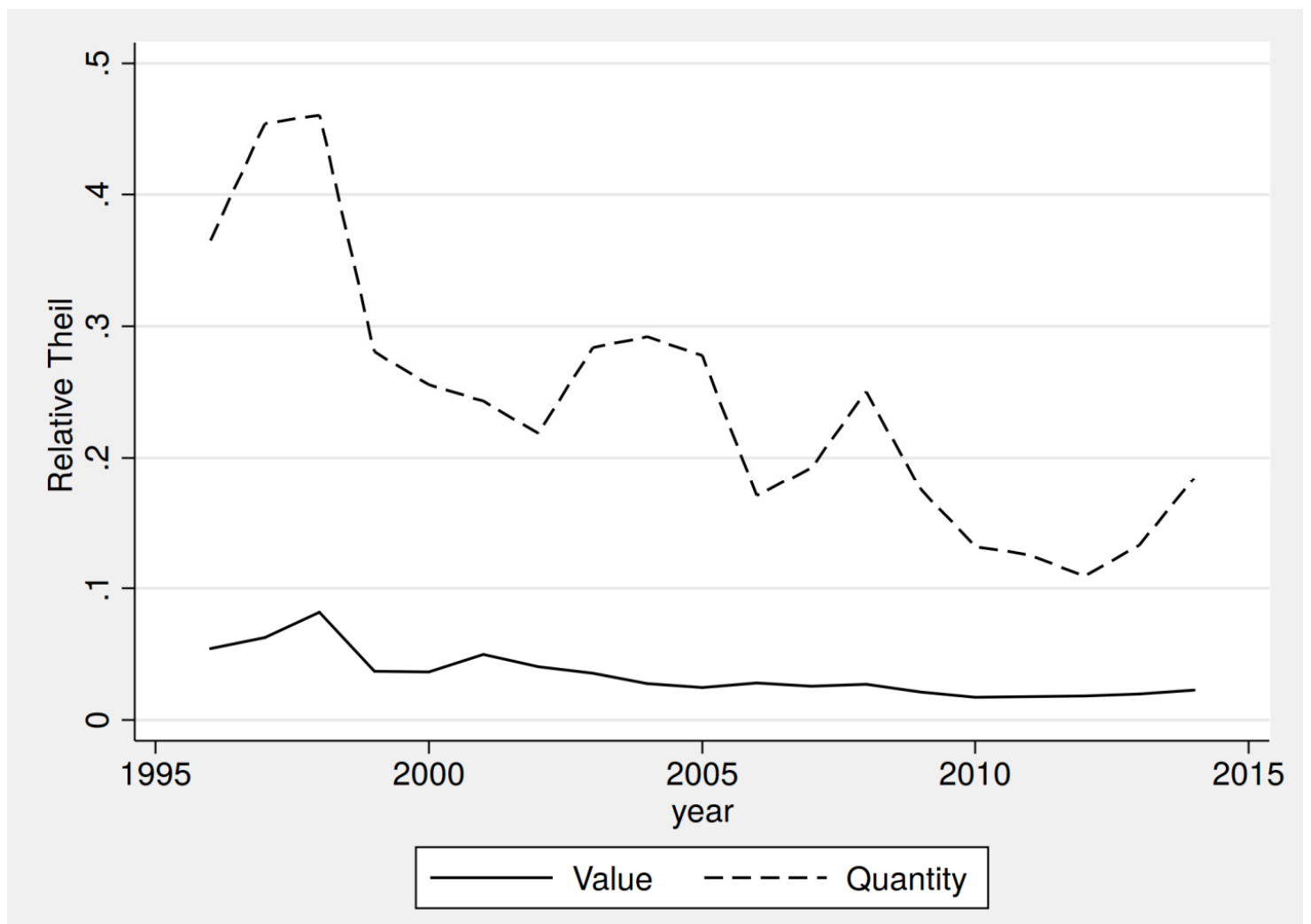

In contrast to the relative Theil index, the absolute version constructed using quantity and value is quite similar, although a systematic difference between the two is seen from 1996-2004 that disappears by 2005 . The absolute Theil index, which is referenced against a uniform spatial distribution, is characterized by two distinct downward trends in concentration punctuated by a temporary sharp increase in absolute concentration in 2005 (Figure 6).

The decrease in absolute concentration that occurs from 1996 through 2003 coincides with a period of sharply increasing landings, a southward shift in the location of the fishery, and increasing importance of the MAB access areas. We interpret this as evidence that the southerly expansion in this period had an equalizing effect across ports. That is, the ports that were small in 1996 grew faster than the ports that were large. The increase in absolute concentration that occurred in 2005-2006 roughly coincides with increasing importance of the GB/SNE access areas relative to the MAB areas and a substantial temporary shift northward in the location of the fishery. Another large decrease in absolute concentration occurs from 2006 to 2010. During this time, landings were roughly constant, varying from 52-61 million pounds, and the MAB access areas were again important relative to the GB/SNE areas. Finally, from 2011-2014, absolute concentration has not displayed any particular trend as landings decreased and the location of the fishery shifted northward substantially. 
Figure 5: Average Latitude of Landing Ports and Catch Locations for Scallops and Other Fishing (weighted by value).

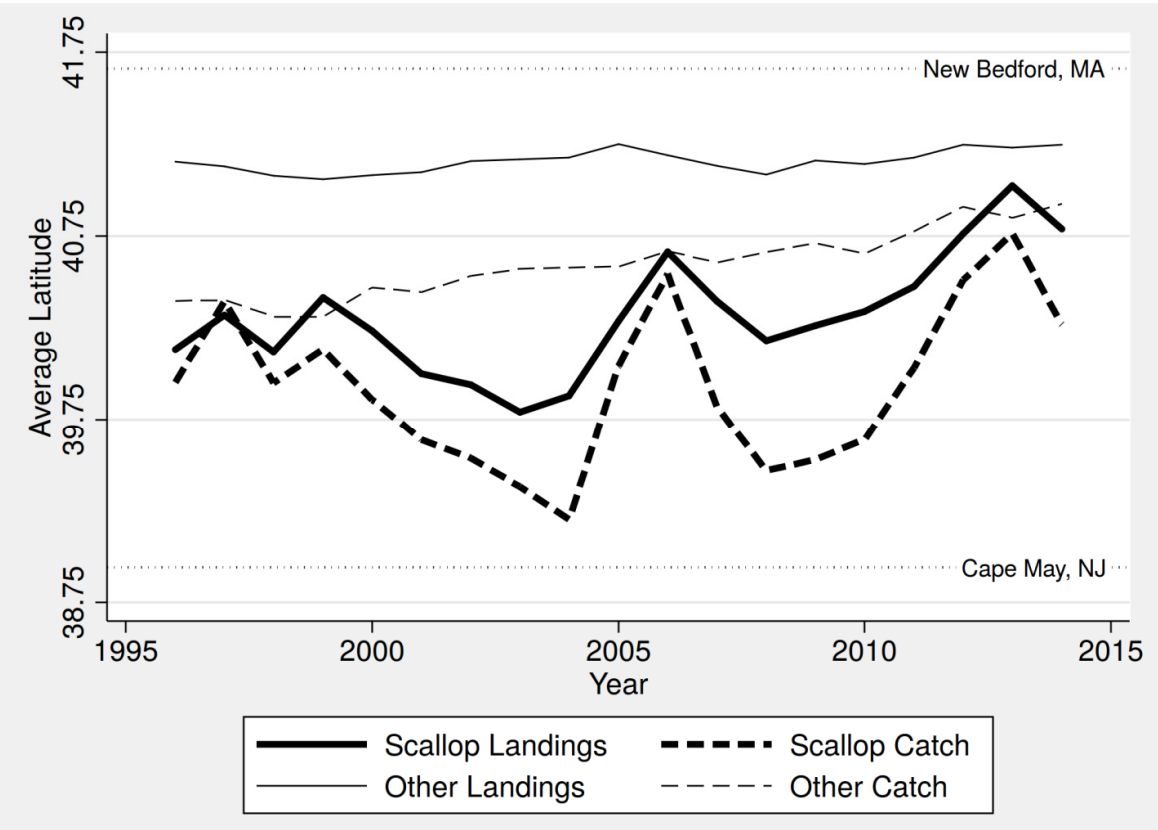

Figure 6: The Absolute Theil Constructed using Value and Quantity.

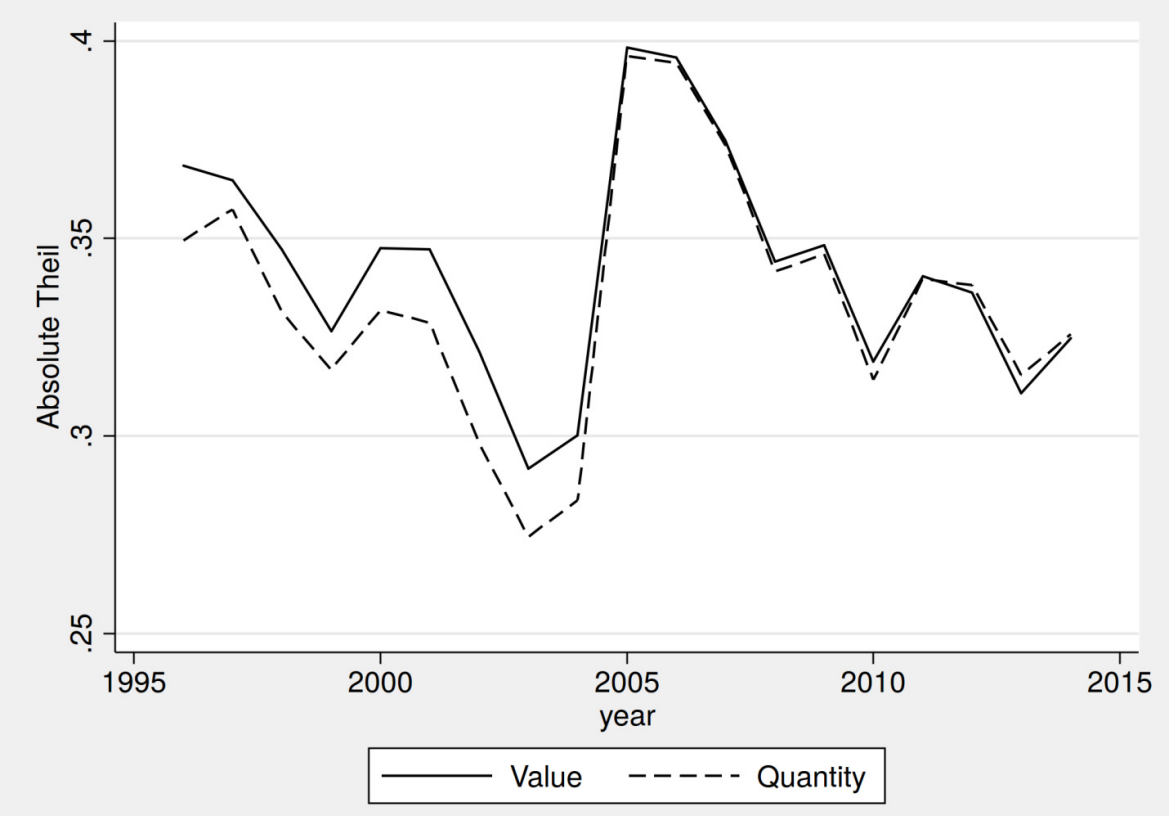

The Theil indices are descriptive and cannot be used for causal inference. Still, these results are consistent with regional differences between the ports in the "north" and "south." When the scallop fishery moves south, the absolute Theil index indicates more dispersed (less concentrated) scallop fishing, suggesting that there are many ports that can service the scallop industry. In contrast, when the fishery moves north, the absolute Theil indicates a more 
geographically concentrated fishery, suggesting that there are comparatively fewer ports in the north that are capable of supporting the scallop industry. The relative Theil index does not correlate nearly as well with the catch locations, suggesting that in both the north and south, scallop fishing increases in the ports in which other fishing is occurring.

\subsection{Spatial Autocorrelation - Global and Local Moran's $I$}

We graph the computed Moran's $I$ along with the $5^{\text {th }}-95^{\text {th }}$ percentiles of Moran's $I$ corresponding to the null hypothesis of complete spatial randomness (Figure 7). Overall, we do not detect a global spatial autocorrelation pattern. It is possible that there are multiple patterns of spatial association that are active in different areas which cannot be detected by a global measure (Fotheringham, 1997; Zhang and Lin, 2007).

We focus on a subset of years $(1998,2003,2006$, and 2014) in our dataset that represent extremes in total output or in relative importance of the open, MAB, or GB areas in the ocean. We augment the typical Moran scatterplot and significance maps with the access and closed area boundaries. Because the Moran scatterplots and significance maps for value and quantities are quite similar, we present only the results based on quantities. The classic Moran scatterplot map allows us to detect spatial association; plotting only the statistically significant ports focuses on those that are in areas with abnormally high or low levels of economic activity.

For all four years illustrated (and all years in our sample), the Moran scatterplot reveals three large low areas for scalloping and two or three high regions (Figure 8). Two of the low areas are at the borders of the study area. Both are related to scallop biology; the waters off North Carolina are too warm for scallops and there are few scallops in the Gulf of Maine. There is a persistent, large high area in Southern New England (Massachusetts, Rhode Island, portions of

Figure 7: Global Moran's I Indicates No Consistent, Dominant Geographic Pattern for Port Level Quantities, Value, and Location Quotients (quantities and value).
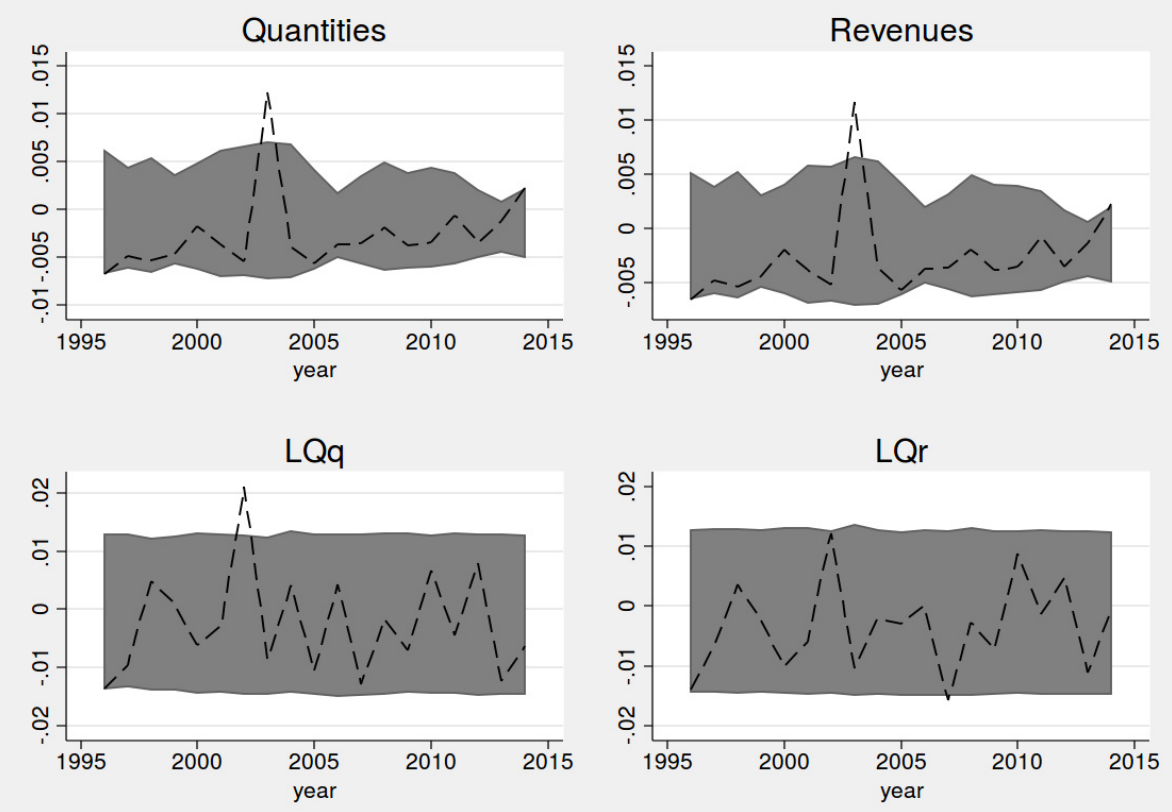

(C) Southern Regional Science Association 2017. 
Connecticut, and Long Island, New York). This region is composed of a few moderately dispersed ports with high landings in regions of high landings $(\mathrm{HH})$, surrounded by numerous ports with low landings in regions with high landings (LH). A smaller high area is in Virginia, this particular region is characterized by a few contiguous $\mathrm{HH}$ ports, surrounded by numerous LH ports. There are also three small high areas in New Jersey; centered at Point Pleasant, Barnegat, and Cape May. These are difficult to visualize on the map because these ports are quite small in size. The Moran scatterplots illustrate why the global Moran's I does not detect spatial association: both positive and negative spatial association appear prevalent.

In 1998, landings were relatively low and there was no access to GB access areas. By 2003, the southern-most "high" area had expanded slightly in size with the opening of access areas in the MAB region. In 2006, when the MAB access areas were closed, the high areas in the south contracted in size while the large high region in southern New England expanded southward to include some ports in New York. The narrative is a bit complex: the major ports in the Mid-Atlantic remained large, despite the closures of nearby access areas. However, they decreased in size enough so that many of the outlying regions were no longer classified as belonging to a high region. This geographic pattern was similar in 2014, when area allocations and catch were low: the southern New England high region expanded south and the large high region in Virginia contracted further.

The Moran significance maps show that many of these regions are not statistically distinguishable from conditional spatial randomness, but do reveal an interesting clustering pattern in Southern Massachusetts. The significance map for 2014 is representative of the time series (Figure 9). The most interesting area is southern Massachusetts, surrounding New Bedford. New Bedford itself is a $\mathrm{HH}$ port, but it is not statistically significant. We interpret this finding to mean that while New Bedford has high landings, the ports located near it have scallop landings that are distributed similarly to chance. In contrast, the areas near New Bedford are classified as statistically significant LH areas: we interpret this to mean that those ports have low landings and the ports nearby (primarily New Bedford) have higher than random landings of scallops. Finally, Fairhaven, located adjacent to New Bedford, is classified as a statistically significant $\mathrm{HH}$ port and is evidence of geographic spillovers.

The Moran scatterplots and significance plots for location quotients illustrate how quickly regulatory and environmental changes affect the scallop industry (Figure 10). In 2003, only the MAB access areas were open and there was a large cluster of scallop-specialized ports in southern Maryland and coastal Virginia. These were likely attracting scalloping activity from adjacent ports. By 2006, when only one GB/SNE access area was open, this specialized cluster had moved north a bit, locating in central New Jersey through Maryland. Some of the formerly scallop-specialized areas in southern Virginia were no longer landing many scallops. The accompanying Moran significance maps confirm parts of this story: the specialized scallop region in Virginia in 2003 was gone by 2006. The Moran scatterplots and significance maps in these years also revealed a specialized scallop region in downeast Maine. These ports reported relatively low landings of scallops and almost no landings of other fish. We strongly suspect that this is an artifact of our dataset: the lobster industry is quite important in Maine, but not subject to mandatory federal reporting. These downeast Maine ports are likely to have relatively high levels of lobster landings and are not likely to be specialized scallop ports. 
Figure 8 - Moran Scatterplots (quantities) for 1998, 2003, 2006, and 2014.

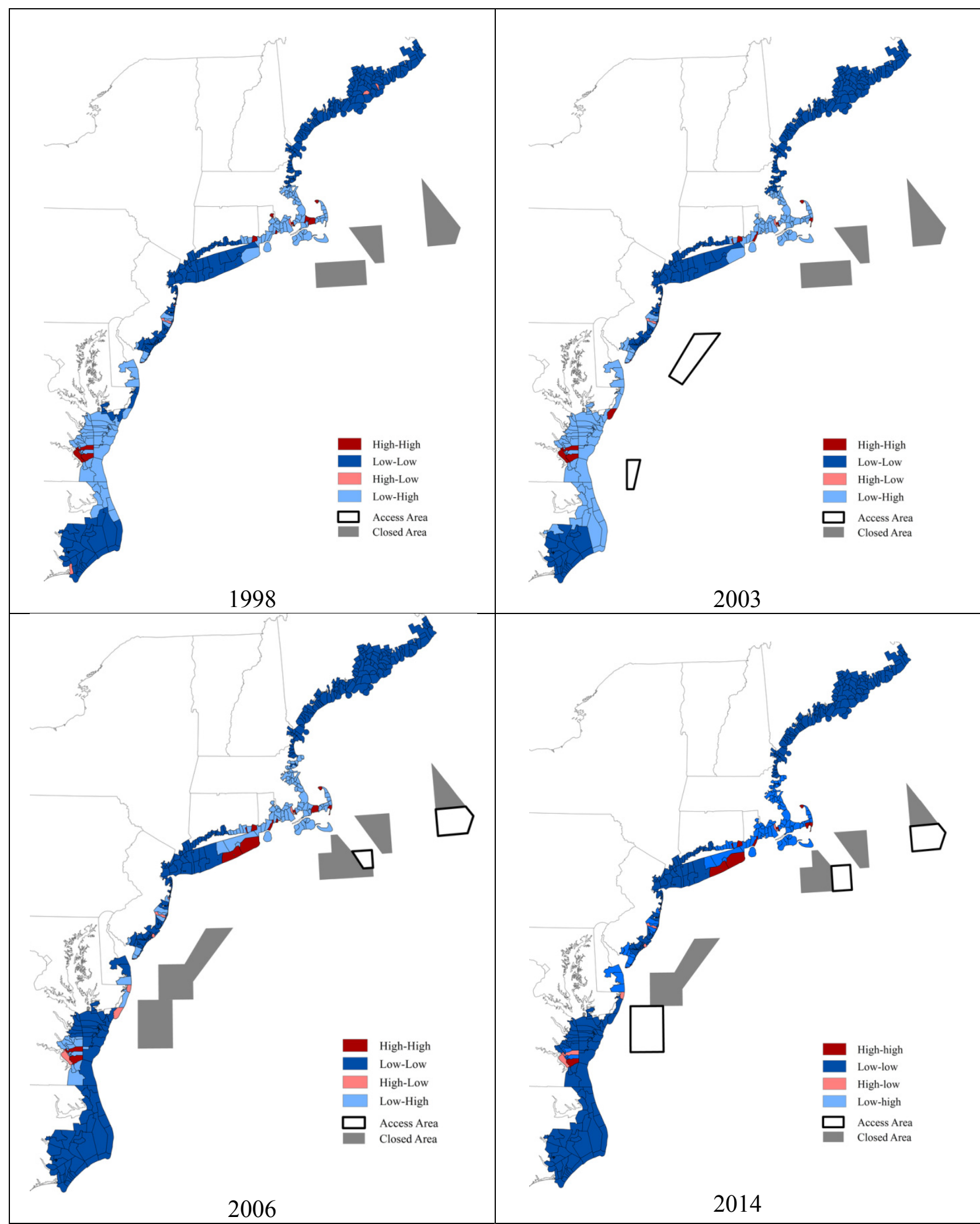

(c) Southern Regional Science Association 2017. 
Figure 9 - Moran Significance Map in 2014.

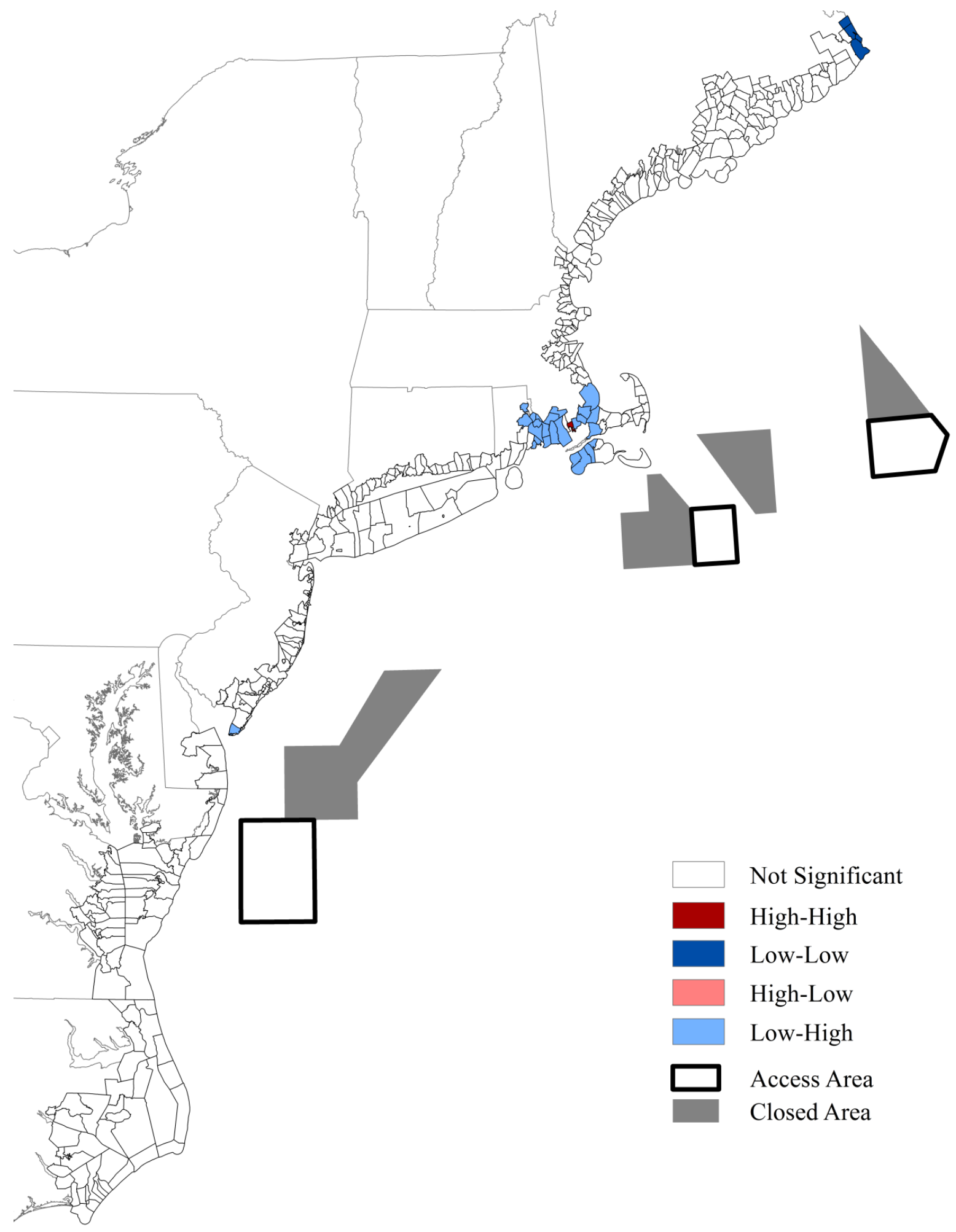

(c) Southern Regional Science Association 2017. 
Figure 10: Moran Scatterplot (top two panels) and Significance Maps (bottom two panels) for 2003 (left panels) and 2006 (right panels) for Location Quotients.

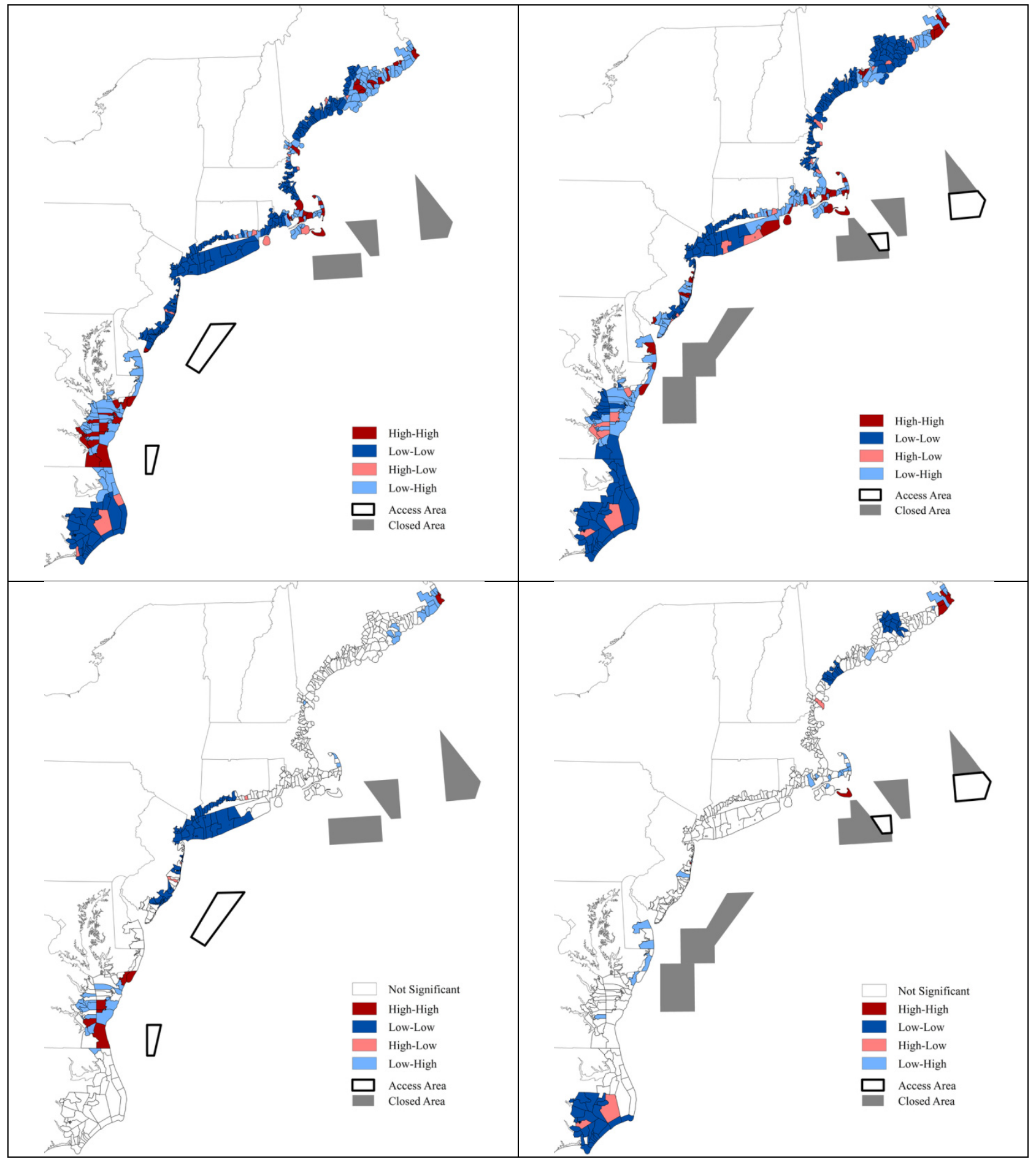

(c) Southern Regional Science Association 2017. 


\section{CONCLUSIONS AND FUTURE RESEARCH}

We have presented an exploratory spatial analysis of production trends in the commercial fishing industry in the Northeast United States, focusing on changes in the concentration of the scallop industry and spatial association of that industry over time. We find large changes in the measures of geographic concentration and local spatial association. The relative Theil index indicates a general trend of convergence: the scallop and overall fishing industry are increasingly located in the same ports. But this convergence trend is nonmonotone, with reversals lasting for multiple years. One of the striking patterns revealed by the concentration indices is the volatility of the geographic concentration of this industry, especially compared to other research which finds relatively smooth changes over time (for example, Brülhart and Traeger, 2005; Cutrini, 2010; Bickenbach, Bode, and Krieger-Boden, 2010). This is, perhaps, not particularly surprising because the location of scallop biomass is quite variable, spatial regulations change frequently, and fishing vessels are quite mobile. We find relatively consistent patterns of spatial association of port-level scallop catch throughout our time series. A few ports that consistently land large amounts of scallops are interspersed among large tracts of the Northeast coast that land minimal amounts of scallops.

The exploratory and descriptive nature of this research is not able to discern the mechanisms by which these changes occur, and understanding the processes that shape the geographic patterns of fishing activity is crucial to understanding how fishing regulations impact communities. Our results suggest that regulations and changes in biomass can shift the locations at which fishing vessels land fish and invites further examination of causal mechanisms by which this can occur. We speculate that increasing geographic convergence may be due to positive spillovers or scale economies that attract fishing fleets to collocate; however, further research is necessary to establish causality. Further understanding of the effects of spatially explicit regulations on fishing vessels and on-shore infrastructure can help fishery managers understand the effects on community and regions.

\section{REFERENCES}

Anselin, Luc. (1995) "Local Indicators of Spatial Association-LISA," Geographical Analysis, 27, 93-115.

Arbia, Giuseppe. (2001) "The Role of Spatial Effects in the Empirical Analysis of Regional Concentration," Journal of Geographical System, 3, 271-281.

Arrow, Kenneth J. (1962) "The Economic Implications of Learning by Doing," Review of Economic Studies, 29,155-173.

Bickenbach, Frank and Eckhardt Bode. (2008) "Disproportionality Measures of Concentration, Specialization, and Localization," International Regional Science Review, 31, 359-388.

Bickenbach, Frank, Eckhardt Bode, and Christiane Krieger-Boden. (2010) "Structural Cohesion in Europe: Stylized Facts.” Kiel Working Paper 1669: Kiel, Germany.

Brodziak, Jon, Steven X. Cadrin, Christopher M. Legault, and Steve A. Murawski. (2008) "Goals and Strategies for Rebuilding New England Groundfish," Fisheries Research, 94, 355-366.

Brülhart, Marius and Rolf Traeger. (2005) "An Account of Geographic Concentration Patterns in Europe," Regional Science and Urban Economics, 35, 597-624.

(C) Southern Regional Science Association 2017. 
Combes, Pierre-Phillipe and Henry G. Overman. (2004) "The Spatial Distribution of Economic Activities in The European Union," Chapter 64 in J. Vernon Henderson and JacquesFrançois Thisse (eds.), Handbook of Regional and Urban Economics-Volume 4: Cities and Geography. North Holland: Amsterdam, pp. 2845-2909.

Cooley, Sarah R., Jennie E. Rheuban, Deborah R. Hart, Victoria Luu, David M. Glover, Jonathen A. Hare, and Scott C. Doney. (2015) "An Integrated Assessment Model or Helping the United States Sea Scallop (Placopecten magellanicus) Fishery Plan Ahead for Ocean Acidification and Warming," PLoS One, 10, e0124145.

De Dominicis, Laura, Giuseppe Arbia, and Henri LF DeGroot. (2013) "Concentration of Manufacturing and Service Sector Activities in Italy: Accounting for Spatial Dependence and Firm Size Distribution," Regional Studies, 47, 405-418.

Edwards, Steve. (2004) “Accounting for Rents in the U.S. Atlantic Sea Scallop Fishery," Marine Resource Economics, 20, 61-76.

Ertur, Cem, Julie Le Gallo, and Catherine Baumont. (2006) "The European Regional Convergence Process, 1980-1995: Do Spatial Regimes and Spatial Dependence Matter?," International Regional Science Review, 29, 3-34.

Fingleton, Bernard. (1999) "Estimates of Time to Economic Convergence: An Analysis of Regions of the European Union," International Regional Science Review, 22, 5-34.

Fotheringham, A. Stewart. (1997) "Trends in Quantitative Methods I: Stressing the Local," Progress in Human Geography, 21, 88-96.

Fujita, Masahisa and Tomoya Mori. (1996) "The Role of Ports in the Making of Major Cities: Self-Agglomeration and Hub-Effect," Journal of Development Economics, 49, 93-120.

Fujita, Masahisa, Tomoya Mori, J. Vernon Henderson, and Yoshitsugu Kanemoto. (2004) "Spatial Distribution of Economic Activities in East Asia," Chapter 65 in J. Vernon Henderson and Jacques-François Thisse (eds.), Handbook of Regional and Urban Economics-Volume 4: Cities and Geography. North Holland: Amsterdam, pp. 29112977.

Guillain, Rachel and Julie Le Gallo. (2010) "Agglomeration and Dispersion of Economic Activities in and Around Paris: An Exploratory Spatial Data Analysis," Environment and Planning B, 37, 961-981.

Hare, Jonathan A., Wendy E. Morrison, Mark W. Nelson, Megan M. Stachura, Eric J. Teeters, Roger B. Griffis, Michael A. Alexander, James D. Scott, Larry Alade, Richard J. Bell, Antonie S. Chute, Kiersten L. Curti, Tobey H. Curtis, Daniel Kircheis, John F. Kocik, Sean M. Lucey, Camilla T. McCandless, Lisa M. Milke, David E. Richardson, Eric Robillard, Harvey J. Walsh, M. Conor McManus, Katrin E. Marancik, and Carolyn A. Griswold. (2016) "A Vulnerability Assessment of Fish and Invertebrates to Climate Change on the Northeast U.S. Continental Shelf," PLoS One, 11, e0146756.

Hart, Deborah R. and Antonie S. Chute. (2004) "Essential Fish Habitat Source Document: Sea Scallop, Placopecten magellanicus, Life History and Habitat Characteristics. $2^{\text {nd }}$ Edition." NOAA Technical Memorandum NMFS-NE-189: Woods Hole, Massachusetts. 
. (2009) "Estimating von Bertalanffy Growth Parameters from Growth Increment Data Using a Linear Mixed-Effects Model with an Application to the Sea Scallop Placopecten magellanicus," ICES Journal of Marine Science, 66, 2165-2175.

Hart, Deborah R. and Paul J. Rago. (2006) "Long-Term Dynamics of US Atlantic Sea Scallop, Placopecten Magellanicus, Populations," North American Journal of Fisheries Management, 26, 490-501.

Hennen, Daniel R., and Deborah R. Hart. (2012) "Shell Height-to-Weight Relationships for Atlantic Sea Scallops (Placopecten magellanicus) in Offshore US Waters," Journal of Shellfish Research, 31, 1133-1144.

Holmes, Thomas J. (1998) "The Effects of State Policies on the Location of Industry: Evidence from State Borders," Journal of Political Economy, 106, 667-705.

Holmes, Thomas J. and John J. Stevens. (2004) "Spatial Distribution of Economic Activities in North America," Chapter 63 in J. Vernon Henderson and Jacques-François Thisse (eds.), Handbook of Regional and Urban Economics_Volume 4: Cities and Geography. North Holland: Amsterdam, pp. 2797-2843.

Jacobs, Jane. (1969) The Economy of Cities. Vintage Books: New York. . (1984) Cities and the Wealth of Nations. Vintage Books: New York.

Krugman, Paul. (1980) "Scale Economies, Product Differentiation, and the Pattern of Trade," American Economic Review, 70, 950-959.

. (1991) "Increasing Returns and Economic Geography," Journal of Political Economy, 99, 483-499.

Lucey, Sean M. and Janet A. Nye. (2010) "Shifting Species Assemblages in the Northeast US Continental Shelf Large Marine Ecosystem," Marine Ecology Progress Series, 415, 2333.

Magnuson-Stevens Fisheries Conservation and Management Reauthorization Act (MSFCMA). (2006) Public Law No 109-479.

Marshall, Alfred. (1890) Principles of Economics. Macmillan: London.

McGarvey, Richard, Fredric M. Serchuk, and Ian A. McLaren. (1992) "Statistics of Reproduction and Early Life History Survival of the Georges Bank Sea Scallop (Placopecten magellanicus) Population," Journal of Northwest Atlantic Fisheries Science, 13, 83-99.

Murphy, Tammy, Andrew Kitts, Chad Demarest, and John Walden. (2015) "2013 Final Report on the Performance of the Northeast Multispecies (Groundfish) Fishery (May 2013-April 2014) $2^{\text {nd }}$ Edition." Northeast Fisheries Science Center Reference Document 15-02: Woods Hole, Massachusetts.

New England Fishery Management Council (NEFMC). "Framework 25 to the Scallop FMP." Newburyport, Massachusetts.

Northeast Fisheries Science Center (NEFSC). (2015) "60th Northeast Regional Stock Assessment Workshop (60th SAW) Assessment Report." Northeast Fisheries Science Center Reference Document 15-08: Woods Hole, Massachusetts.

(C) Southern Regional Science Association 2017. 
Ohlin, Bertil. (1967) Interregional and International Trade. Harvard Economic Studies Volume 39. Harvard University Press: Cambridge, Massachusetts.

Pinksy, Malin L. and Michael Fogarty. (2012) "Lagged Social-Ecological Responses to Climate and Range Shifts in Fisheries," Climatic Change, 115, 883-891.

Repetto, Robert. (2002) "Creating Asset Accounts for a Commercial Fishery Out of Equilibrium: A Case Study of the Atlantic Sea Scallop Fishery," Review of Income and Wealth, 48, $245-259$.

Romer, Paul M. (1986) "Increasing Returns and Long-Run Growth," Journal of Political Economy, 94, 1002-1037.

Sarro, Christopher L., and Kevin DE Stokesbury. (2009) "Spatial and Temporal Variation in the Shell Height/Meat Weight Relationship of the Sea Scallop Placopecten magellanicus in the Georges Bank Fishery," Journal of Shellfish Research, 28, 497-503.

Tian, Rucheng C.., Changsheng Chen, Kevin D. E. Stokesbury, Brian J. Rothschild, Geoffrey W. Cowles, Qichun Xu, Song Hu, Bradley P. Harris, and Michael C. Marino II. (2009) "Modeling the Connectivity Between Sea Scallop Populations in the Middle Atlantic Bight and over Georges Bank," Marine Ecology Progress Series, 380, 147-160.

Tremblay, M. John, John W. Loder, Francisco E. Werner, Christopher E. Naimie, Fred H. Page, and Michael M. Sinclair. (1994) "Drift of Sea Scallop Larvae Placopecten magellanicus on Georges Bank: A Model Study of the Roles of Mean Advection, Larval Behavior, and Larval Origin,” Deep Sea Research Part II: Topical Studies in Oceanography, 41, 7-49.

Zhang, Tonglin and Ge Lin. (2007) "A Decomposition of Moran's I for Clustering Detection," Computational Statistics and Data Analysis, 51, 6123-6137.

(C) Southern Regional Science Association 2017. 